\title{
Newly Isolated High Squalene Producing Thraustochytrid Strain Aurantochytrium sp. P5/2 from Mangrove Habitats in Nakhon Si Thammarat Province, Thailand
}

\author{
Tarnhatai MALAWET ${ }^{1}$, Phuwadol BANGRAK ${ }^{2}$, \\ Yuwadee PEERAPORNPISAL ${ }^{3}$ and Niyom KAMLANGDEE ${ }^{2, *}$ \\ ${ }^{I}$ Faculty of Education, Nakhon Si Thammarat Rajabhat University, Nakhon Si Thammarat 80280, Thailand \\ ${ }^{2}$ School of Science, Walailak University, Nakhon Si Thammarat 80161, Thailand \\ ${ }^{3}$ Faculty of Science, Chiang Mai University, Chiang Mai 50200, Thailand
}

('Corresponding author's e-mail: kniyom@gmail.com)

Received: 1 March 2019, Revised: 6 June 2019, Accepted: 18 July 2019

\begin{abstract}
Thraustochytrids are alternative potential sources of squalene, because they grow rapidly, are relatively easy to culture, and accumulate in large amounts. The objectives of this research were to isolate squalene-producing Thraustochytrids from fallen leaves in Paknakon Bay, including Paknakon Mangrove forest $(\mathrm{N})$, Pakpanang Mangrove forest (P) and Thasala Mangrove forest $(\mathrm{T})$, Nakhon Si Thammarat, Thailand, and to investigate their total lipid profile and squalene contents. A total of nine Thraustochytrid isolates were obtained.Morphological and molecular features revealed that those Thraustochytrids belonged to the genus Aurantiochytrium (N1, N14, P1/1, P5/2, P6/1, P43, T1, T26, and T42). Subsequently, they were cultivated and their cell dry weight, fatty acid compositions, and squalene contents were analyzed. At $96 \mathrm{~h}$ of cultivation, the dry cell weights ranged from 7.51 to $17.43 \mathrm{mg} / \mathrm{g}$. The total lipid profile showed a broad spectrum of saturated fatty acids with an abundance of palmitic acid (16:0), 24.72 - $41.06 \%$ TFA, pentadecanoic acid (15:0) 16.75 - $28.48 \%$ TFA, heptadecanoic acid (17:0) 4.19 - $7.67 \%$ TFA, lignoceric acid (24:0) 2.76 - $8.83 \%$ TFA, myristic acid (14:0) 2.17 - $3.43 \%$ TFA, stearic acid (18:0) $0.83-1.32 \%$ TFA, arachidic acid (20:0) $0.19-0.33 \%$ TFA, and behenic acid (22:0) $0.19-0.21 \%$ TFA, respectively. Unsaturated fatty acids, including Docosahexaaenoic acid $(22: 6 ; 8.59$ $35.99 \%$ TFA), Clupanodonic acid (22:5, 2.24 - $8.94 \%$ TFA), Arachidonic acid (20:4, $0.32-0.60 \%$ TFA), Eicosapentaenoic acid (20:5, $0.19-0.62 \%$ TFA), Linolenic acid (18:3, $0.12-0.18 \%$ TFA), and Erucic acid (22:1; $0.02-0.09 \%$ TFA) were also found. The squalene contents ranged from 0.06 to 4.78 $\mathrm{mg} / \mathrm{g}$. The highest biomass and squalene-accumulation was achieved from strain P5/2, which was identified as Aurantiochytrium sp.ม with a maximum yield of $4.78 \mathrm{mg} / \mathrm{g}$ at $96 \mathrm{~h}$ of cultivation.
\end{abstract}

Keywords: Aurantiochytrium, fatty acid contents, mangrove ecosystem, squalene, Thraustochytrids

\section{Introduction}

Squalene,2,6,10,15,19,23 - hexamethyltetracosa -2,6,10,14,18,22 - hexaene, is a dehydrotriterpenic hydrocarbon $\left(\mathrm{C}_{30} \mathrm{H}_{50}\right)$ with six double bonds. It acts as a precursor of cholesterol, bile acids, and all steroids in plants and animals [1-3]. Squalene is extensively used as an excipient in pharmaceutical emulsions for the delivery of vaccines, drugs, and other medicinal substances. It improves the immune system and is therefore used as a protective agent in cancer treatment. It is also used as a hydrating and antioxidant agent in cosmetics [4,5]. Dietary squalene is able to stimulate nonspecific immune functions in a dose-dependent manner, influence cholesterol absorption, and reduce low-density lipoprotein (LDL) 
as well as triglyceride levels in individuals presenting hypercholesterolemia. A dose of $500 \mathrm{mg}$ of squalene/day was suggested in normalizing lipid values for the nutritional health of human beings [6].

Currently, the major commercial sources of squalene are the liver oil of deep-sea sharks and plant seeds $[7,8]$. The future supply of shark liver oils, however, is limited by the availability as a result of international concern for the conservation of marine ecology [1], as well as other obstacles, such as environmental organic pollutants and heavy metals [9]. Alternative squalene sources include vegetable oils, where the highest quantities are found in Amaranth and olive oil, on average $7-8 \%(\mathrm{w} / \mathrm{w})$ and $1 \%$, respectively [10]. Squalene from plant seed oils, such as olive oil (ca. $7 \mathrm{mg} / \mathrm{g})$ and Amaranthus seed oil (0 - $5.64 \mathrm{mg} / \mathrm{g}$ ) [1] are not desirable for squalene production due to their own limitations, including the effects of locality and seasonal variation of crop productivity [11]. There is the need, therefore, to secure a sustainable and safe source of squalene.

Thraustochytrids are unicellular, eukaryote, heterotrophic, and obligate marine microorganisms, commonly found in seawater and sediments, with the highest abundance in nutrient-rich areas, such as mangrove forests $[12,13]$. They are currently being used as a producer of polyunsaturated fatty acids, and some species possess relatively high contents of squalene, which could be purified easily by countercurrent chromatography [14-16]. With a better understanding of their squalene contents, the biomass of Thraustochytrids will be a value-added product in food and feed industries, which will have wider commercial applications and increased economic influence. Therefore, an investigation of the squalene content of Thraustochytrid is necessary to further explore in this microalgal resource.

In this study, Thraustochytrids were isolated from mangroves in Nakhon Si Thammarat province. Their fatty acid compositions and squalene contents were analyzed, and the highest squalene-producing strain was further identified with phylogenic analysis. Changes of squalene content and cell growth characteristics of the identified strain during different phases of cultivation were subsequently investigated. The results obtained from this research will provide a basic knowledge of squalene production in polyunsaturated fatty acid producing Thraustochytrids and will be useful for further identifying the role of squalene in cells.

\section{Materials and methods}

\section{Isolation of Thraustochytrids}

Fallen leaves were randomly collected from the three selection areas of Paknakhon, Pakphanang, and Thasala mangrove forest. The leaf samples were washed with sterile sea water to reduce the chance of contamination before spreading the samples onto GYP agar plates containing glucose $(20 \mathrm{~g} / \mathrm{L})$, yeast extract $(10 \mathrm{~g} / \mathrm{L})$, micrological peptone $(5 \mathrm{~g} / \mathrm{L})$, and artificial sea water $(50 \% \mathrm{v} / \mathrm{v})$ at $\mathrm{pH} 6.5$. These GYP agar plates were further supplemented with an antibiotic mixture $(300 \mathrm{mg} / \mathrm{L}$ Streptomycin and Penicillin $\mathrm{G})$ and incubated at $25{ }^{\circ} \mathrm{C}$ for three to seven days until colonization appeared [23]. The colonies were examined under a microscope $(40 \mathrm{X})$ for their colony morphological structures. Thraustochytrid-like colonies were selected and streaked onto new GYP agar plates and repeatedly sub-cultured on freshly prepared GYP agar plates until axenic cultures were obtained.

\section{Morphological observation of Thraustochytrids}

Axenic cultures of Thraustochytrid strains were sub-cultured using a sterilized inoculating loop, streaked across GYP agar plates, and incubated at $25^{\circ} \mathrm{C}$ for three to seven days. Colonies appearing on the GYP agar plates were transferred to $3 \mathrm{~mL}$ seawater GYP broth and incubated at $25{ }^{\circ} \mathrm{C}$. The cell suspension of Thraustochytrid strains $(100 \mu \mathrm{l})$ were transferred into a slide chamber for microscopic observation. The morphological characteristics, such as presence of ectoplasmic nets, formation of zoospores, amoeboid cells, vegetative cells, zoospores and zoosporangia, were observed in the Thraustochytrid strains during cell cycle development [17].

Cell dry weight determination

All isolates of Thraustochytrid strains were cultured in sterile GYP agar plates containing glucose $(20 \mathrm{~g} / \mathrm{L})$, yeast extract $(10 \mathrm{~g} / \mathrm{L})$, and micrological peptone $(5 \mathrm{~g} / \mathrm{L})$ in $50 \%$ artificial seawater [18]. The 
http://wjst.wu.ac.th

isolates were inoculated in $50 \mathrm{~mL}$ of GYP broth and kept at $20{ }^{\circ} \mathrm{C}$ with a shaker speed of $150 \mathrm{rpm}$. The Thraustochytrid cell pellets were obtained through centrifugation. The pellets were freeze-dried and weighed until constant weights were obtained. The freeze-dried cells were stored at $-20{ }^{\circ} \mathrm{C}$ before proceeding with lipid extraction.

\section{Fatty acid analysis}

Fatty acid composition of the freeze-dried Thraustochytrid samples were determined according to the method of [14]. Nonadecanoic acid (C19:0) was used as the internal standard. An HP 7890 capillary gas chromatograph (Hewlett- Packard, Palo Alto, CA) equipped with a flame ionization detector and a 30 $\mathrm{m} \times 0.25 \mathrm{~mm}$ i.d. Innowax capillary column (J\&W Scientific, Folsom, CA), was used for fatty acid analysis with nitrogen as the carrier gas. The fatty acids were identified by chromatographic comparison with authentic standards (Sigma Chemical Co., St. Louis, MO), and the quantities were estimated from peak areas on the chromatogram with that of the internal standard.

\section{Squalene analysis}

Squalene was analyzed by GC-MS according to the method of [19]. The freeze-dried cells (100 $\mathrm{mg}$ ) were saponified in $4 \mathrm{~mL}$ of $10 \% \mathrm{KOH}(\mathrm{w} / \mathrm{v}) / 75 \%$ ethanol $(\mathrm{v} / \mathrm{v})$ solution at $50{ }^{\circ} \mathrm{C}$ for 15 min and were extracted three times with hexane. The extracts were dried under nitrogen gas and resuspended in $2.0 \mathrm{~mL}$ of acetonitrile. The prepared samples were then separated and determined by the Agilent GC 7890A gas chromatography system equipped with a fused silica capillary column $(30 \mathrm{~m} \times 0.25 \mathrm{~mm}$ i.d., $0.25 \mu \mathrm{m}$ film thickness: Mega-5MS). Helium (99.999 \%) was used as the carrier gas, with a flow rate of $1 \mathrm{~mL} / \mathrm{min}$ at a constant flow in the split mode (10:1). Squalene was identified by comparison with authentic standard (Sigma Chemical Co.).

\section{DNA extraction and amplification of the $18 S$ rRNA Gene}

DNA extraction was performed using the modified protocol of Mo et al. [20]. Cultures were centrifuged at $12,000 \mathrm{rpm}$ for $1 \mathrm{~min}$, supernatant was discarded, and buffer extraction was added on pellet (0.2 M Tris- $\mathrm{HCl} \mathrm{pH}$ 8.0, $1.4 \mathrm{M} \mathrm{NaCl}, 0.1 \mathrm{M}$ EDTA and $1.5 \%$ SDS) and vortexed with fine sand for 1 min. Isoamyl alcohol was added and mixed for $1 \mathrm{~min}$. Then, the solution was centrifuged at $12,000 \mathrm{rpm}$ for $10 \mathrm{~min}$, and the supernatant was transferred to a new tube. The aqueous phase was precipitated with $3 \mathrm{M}$ sodium acetate solution $(\mathrm{pH} 5.2)$ before being stored at $-20{ }^{\circ} \mathrm{C}$ for $30 \mathrm{~min}$. The mixture was centrifuged at $12,000 \mathrm{rpm}$ for $10 \mathrm{~min}$. The DNA precipitation was washed in $70 \%$ ethanol and centrifuged at $12,000 \mathrm{rpm}$ for $5 \mathrm{~min}$. The DNA pellet was resuspended in $50 \mu \mathrm{L}$ sterile water and incubated in a water bath at $50{ }^{\circ} \mathrm{C}$ for $30 \mathrm{~min}$ before the purification of DNA pellet was checked by OD. $260 / 280$. Finally, the intact DNA was analyzed on $1.5 \%$ agarose gel electrophoresis and stained with ethidium bromide.

PCR amplification of $18 \mathrm{~S}$ rRNA gene was carried out using commercial kit GoTaq ${ }^{\circledR}$ Green Master Mix (Reaction Buffer $\mathrm{pH} 8.5,400 \mu \mathrm{M}$ of dNTPs Promega and $3 \mathrm{mM} \mathrm{MgCl}_{2}$ ), and Genomic DNA (with an average ratio 260/280 of 1.6) and $1 \mathrm{mM}$ of specific primers (FA1 5'AAAGATTAAGCCATGCATGT3', RA1 5'AGCTTTTTAACTGCAACAAC-3'; FA2 5'-GTCTGGTGCCAGCAGCCGCG3',RA25'CCCGTGTTGAGTCAAATTAAG-3'; FA3 5'CTTAAAGGAATTGACGGAAG-3' and RA3 5'CAATCGGTAGGTGCGACGGGCGG-3') [21]. DNA amplification was performed with an initial denaturation step of $3 \mathrm{~min}$ at $95{ }^{\circ} \mathrm{C}$ with 30 cycles of amplification $\left(1 \mathrm{~min} 95{ }^{\circ} \mathrm{C}, 30 \mathrm{~s} 58{ }^{\circ} \mathrm{C}\right.$ and 1 min $72{ }^{\circ} \mathrm{C}$ ), and final elongation at $72{ }^{\circ} \mathrm{C}$ of $10 \mathrm{~min}$. The PCR fragments were visualized on $1.5 \%$ agarose gel using $10 \mu \mathrm{g} / \mathrm{mL}$ of ethidium bromide.

\section{Phylogenetic analysis}

The PCR products were sequenced by a private company (Biodesign, Thailand, and Maccrogen, Korea). Phylogenetic tree analysis was performed by phylogeny programs PhyML and TreeDyn. Specie relations were evaluated with statistical analysis through the bootstrap protocol. To group the phylogenetic analysis of the family Thraustochytriaceae, the Prorocentrum genus was used as outgroup. 


\section{Results and discussion}

The isolation of Thraustochytrid strains were processed from the three different samples sites of Paknakhon; N (GPS coordinates $\left.8^{\circ} 16^{\prime} 37^{\prime \prime} \mathrm{N} 100^{\circ} 09^{\prime} 31^{\prime \prime} \mathrm{E}\right)$, Pakphanang; P (GPS coordinates $8^{\circ} 28^{\prime}$ $32^{\prime \prime} \mathrm{N} 100^{\circ} 06^{\prime} 35^{\prime \prime} \mathrm{E}$ ) and Thasala mangrove forest; $\mathrm{T}$ (GPS coordinates $8^{\circ} 37^{\prime} 47^{\prime \prime} \mathrm{N} 99^{\circ} 56^{\prime} 44^{\prime \prime} \mathrm{E}$ ). Fallen leaves of Rhizophora mucronata were randomly collected and physiochemical properties were analyzed. The leaf samples were dark brown with pH $6.8-7.8$ and salinity of 24-35 ppt. The average temperature of the sampling sites was between 25 and $26{ }^{\circ} \mathrm{C}$. Nine cultures were isolated and preliminarily identified as Thraustochytrids according to the method described in [17]. Heterotrophic growth characteristics, fatty acid composition, and squalene content of all isolates were investigated before further phylogenetic identification.

The selected Thraustochytrids can be categorized into four major groups based on morphological features (Table 1). The isolated strains were obtained from decaying mangrove leaves by direct plating technique, and antibiotics were added to the samples to avoid the growth of other microorganisms.

Table 1 Morphological features of the examined Thraustochytrid strains

\begin{tabular}{|c|c|c|c|c|c|c|}
\hline Group & Colony morphology & Ectoplasmic net & $\begin{array}{c}\text { Shape and size of } \\
\text { vegetative cells }\end{array}$ & $\begin{array}{l}\text { Cell } \\
\text { wall }\end{array}$ & $\begin{array}{c}\text { Amoeboid } \\
\text { cell }\end{array}$ & $\begin{array}{c}\text { Binary cell } \\
\text { division }\end{array}$ \\
\hline $\begin{array}{l}\text { I } \\
\text { N1,N14, } \\
\text { P1/1,P61, } \\
\text { P43,T42 }\end{array}$ & $\begin{array}{l}\text { Circular colonies, } \\
\text { white, raised with an } \\
\text { entire margin }\end{array}$ & Present & $\begin{array}{l}\text { Globose, } \\
10-20 \mu \mathrm{m} \text { diam. }\end{array}$ & Thin & Present & Present \\
\hline $\begin{array}{l}\text { II } \\
\text { T26 }\end{array}$ & $\begin{array}{l}\text { Irregular colonies, } \\
\text { white, flat with an } \\
\text { undulate margin }\end{array}$ & Present & $\begin{array}{l}\text { Subglobose, } \\
15-20 \mu \mathrm{m} \text { diam. }\end{array}$ & Thin & Present & Present \\
\hline $\begin{array}{l}\text { III } \\
\text { T1 }\end{array}$ & $\begin{array}{l}\text { Circular colonies, } \\
\text { orange, raised with an } \\
\text { undulate margin }\end{array}$ & Present & $\begin{array}{l}\text { Globose, } \\
10-15 \mu \mathrm{m} \text { diam. }\end{array}$ & Thin & Present & Present \\
\hline $\begin{array}{l}\text { IV } \\
\text { P5/2 }\end{array}$ & $\begin{array}{l}\text { Circular colonies, } \\
\text { cream, raised with an } \\
\text { entire margin }\end{array}$ & Present & $\begin{array}{l}\text { Globose, } \\
20-26 \mu \mathrm{m} \text { diam. }\end{array}$ & Thin & Present & Present \\
\hline
\end{tabular}

Most of the Thraustochytrid strains were found in three colony colors: white, creamy and orange, similar to those found and reported in Australia and India [18]. Colony elevations were raised, and the surfaces were dull. Mature colonies were either spherical or irregular in shape, and most of the colonies were moderate to large in size.

The Thraustochytrid strains were visualized under a microscope at $40 \times$ and $100 \times$ magnification to determine cell size and shape. The cell size of the strains isolated from research areas ranged from $10 \mu \mathrm{m}$ to $26 \mu \mathrm{m}$, with an average cell size of $18 \mu \mathrm{m}$ for most strains (Figure 1). The average cell size of Pakphanang isolates was comparatively larger than those of Paknakhon and Thasala isolates. 


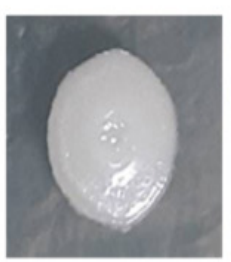

(A)

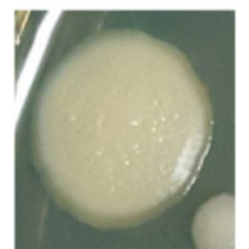

(G)

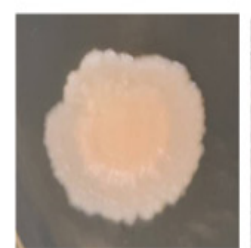

(M)

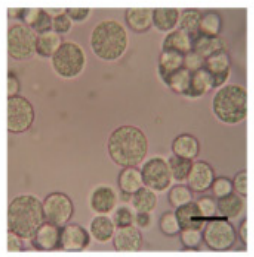

(B)

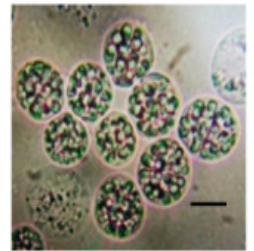

(H)

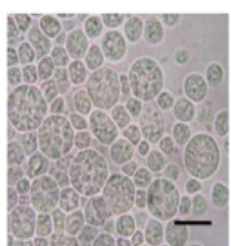

(N)

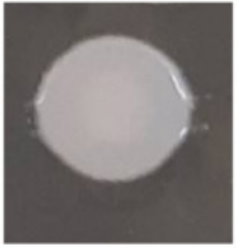

(C)

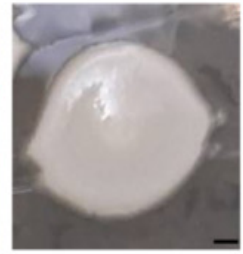

(I)

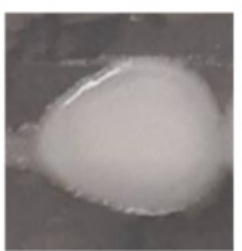

(O)

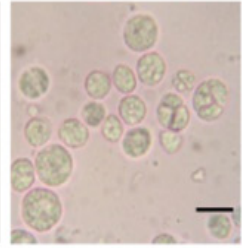

(D)

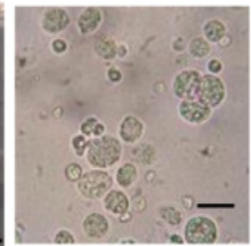

(J)

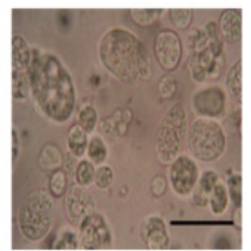

(P)

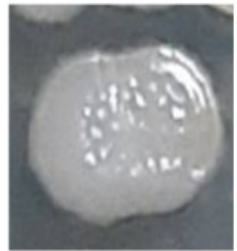

(E)

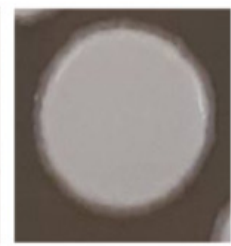

(K)

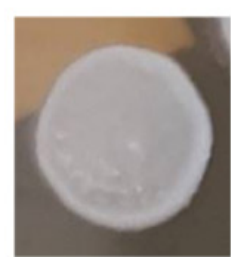

(Q)

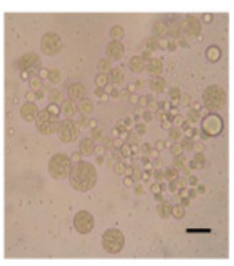

(F)

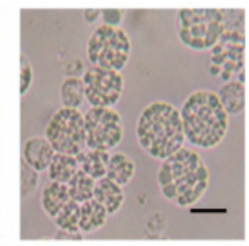

(L)

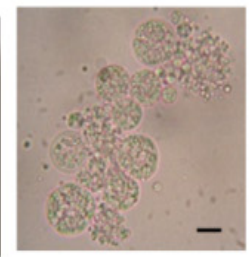

(R)

Figure 1 Thraustochytrid colonies and cells, Aurantiochytrium N1 (A-B), Aurantiochytrium N14 (C-D), Aurantiochytrium P1/1 (E-F), Aurantiochytrium P5/2 (G-H), Aurantiochytrium P6/1 (I-J), Aurantiochytrium P43 (K-L), Aurantiochytrium T1 (M-N), Aurantiochytrium T26 (O-P), and Aurantiochytrium T42 (Q-R). (scale bar $=20 \mu \mathrm{m})$ isolates

Growth characteristics, fatty acid composition, and squalene contents of Thrausthochytrid

The nine Thraustochytrid strains were cultured in $50 \mathrm{~mL}$ of GYP broth with a shaker speed of 150 $\mathrm{rpm}$ at $25{ }^{\circ} \mathrm{C}$ for 4 days. The highest biomass production was attained from Pakphanang samples (between $8.98 \mathrm{~g} / \mathrm{L}$ to $17.43 \mathrm{~g} / \mathrm{L}$ ), Thasala (between $9.19 \mathrm{~g} / \mathrm{L}$ to $16.14 \mathrm{~g} / \mathrm{L}$ ), and Paknakhon strains (between $7.51 \mathrm{~g} / \mathrm{L}$ to $8.16 \mathrm{~g} / \mathrm{L}$ ), respectively (Table 2).

Among Pakphanang isolates, Aurantiochytrium sp. P5/2 produced the highest biomass at $17.43 \mathrm{~g} / \mathrm{L}$, followed by Aurantiochytrium sp. P1/1 at $15.05 \mathrm{~g} / \mathrm{L}$, and Aurantiochytrium sp. P43 at $12.22 \mathrm{~g} / \mathrm{L}$, and the lowest biomass was recorded in Aurantiochytrium sp. P6/1 at $8.98 \mathrm{~g} / \mathrm{L}$. For Thasala Thraustochytrids, the maximum and minimum biomass were recorded in Aurantiochytrium sp. T1 (16.14 g/L) and Aurantiochytrium sp. T42 (9.19 g/L). In Paknakhon isolates, the highest biomass was obtained from Aurantiochytrium sp. N1 (8.16 g/L) and Aurantiochytrium sp. N14 (7.5 g/L), respectively (Table 2). 
http://wjst.wu.ac.th

Table 2 Squalene contents of nine Thraustochytrid isolates ${ }^{\mathrm{a}}$

\begin{tabular}{ccc}
\hline Strain & Biomass $(\mathbf{g} / \mathbf{L})$ & Squalene content $(\mathbf{m g} / \mathbf{g})$ \\
\hline N1 & $8.16 \pm 0.01$ & $2.82 \pm 1.76$ \\
N14 & $7.51 \pm 0.01$ & $0.07 \pm 0.08$ \\
P1/1 & $15.05 \pm 0.0$ & $0.1 \pm 0.00$ \\
P5/2 & $17.43 \pm 0.02$ & $4.78 \pm 1.76$ \\
P6/1 & $8.98 \pm 0.02$ & $1.98 \pm 0.61$ \\
P43 & $12.22 \pm 0.00$ & $3.14 \pm 0.23$ \\
T1 & $16.14 \pm 0.00$ & $0.21 \pm 0.13$ \\
T26 & $15.92 \pm 0.01$ & $0.06 \pm 0.03$ \\
T42 & $9.20 \pm 0.00$ & $0.11 \pm 0.01$ \\
LSD $(\mathrm{p}<0.05)^{\mathrm{b}}$ & 0.0078 & 0.1409 \\
\hline
\end{tabular}

${ }^{a}$ Data are expressed as mean (standard deviation of three replicates). ${ }^{b}$ LSD $(p<0.05)$, the least significant difference was used for difference comparison among means of various strains

The data in Table 2 indicated that Aurantiochytrium sp. P5/2 from Pakphanang area grew rapidly and yielded the highest biomass concentration $(17.43 \mathrm{~g} / \mathrm{L})$ at $96 \mathrm{~h}$ of cultivation. In comparison to other squalene-producing microorganisms, the highest biomass of Shizochytrium mangrovei and Thraustochytrium sp. were only $7 \mathrm{mg} / \mathrm{L}$ and $2.79 \mathrm{mg} / \mathrm{L}$, respectively [22]. Therefore, the rapid growth of Aurantiochytrium sp. P5/2 was a benefit for its commercial application.

The fatty acid profiles of Thraustochytrid isolates from the south of Thailand were similar to the major constituents of palmitic acid (C16: 0) (Table 3). The content of palmitic acid reached 41.06, 40.29, and $39.37 \%$ TFA from Pakphanang, Thasala, and Paknakhon mangrove forests, respectively. These results are similar to other findings from [22], who found that Schizochytrium sp. and Thraustochytrium sp. were able to produce 39 and $42 \%$ of TFA of palmitic acid (C16: 0), respectively. In addition, high amounts of palmitic acid (C16:0) were obtained at $2 \%$ glucose, and this compound has potential applications for products such as soup and salad oil. Hence, these organisms can be considered as renewable sources for biodiesel production. The Aurantiochytrium sp. P1/1 produces maximum palmitic acids of about $41.06 \%$ of TFA. Since DHA-production of Thraustochytrids isolated in this study range of $8.59-35.99 \%$ of TFA, the isolate with the most potential for DHA production in our study was the Aurantiochytrium sp. N1, as it accumulated $35.99 \%$ of TFA. This is an alternative source for DHA and, thus, fish oil replacement in aquaculture and as a sustainable energy source for biodiesel production. In addition, DHA is of interest due to its applications in nutraceuticals, infant formula, fish feed, etc. To sum up, Aurantiochytrium sp. N1 is thought to be a promising resource for microbial DHA production, giving a good level of productivity as well as a simple polyunsaturated fatty acid. 
http://wjst.wu.ac.th

Table 3 Fatty acid composition of nine Thraustochytrid isolates ${ }^{\mathrm{a}}$

\begin{tabular}{|c|c|c|c|c|c|c|c|c|c|}
\hline \multirow{2}{*}{ Fatty acids } & \multicolumn{9}{|c|}{ Fatty acid content ( $\%$ of CDW) } \\
\hline & N1 & N14 & P1/1 & $\mathbf{P 4 3}$ & $\mathrm{P5} / 2$ & P6/1 & T1 & $\mathbf{T 2 6}$ & T42 \\
\hline Capric acid (C10:0) & 0.11 & 0.38 & 0.18 & 0.06 & 0.07 & 0.08 & 0.37 & 0.39 & 0.07 \\
\hline Undecanoic acid (C11:0) & 0.04 & 0.97 & 0.05 & nd & $\mathrm{Nd}$ & nd & 0.39 & 0.21 & nd \\
\hline Lauric acid (C12:0) & 0.09 & 1.51 & 0.14 & 4.45 & 4.72 & 5.37 & 1.89 & 1.61 & 4.11 \\
\hline Tridecanoic acid (C13:0) & 0.32 & 0.48 & 0.35 & 0.27 & 0.28 & 0.25 & 0.48 & 0.56 & 0.25 \\
\hline Myristic acid (C14:0) & 2.17 & 2.74 & 3.43 & 2.79 & 2.78 & 2.59 & 2.74 & 2.72 & 2.58 \\
\hline Pentadecanoic acid (C15:0) & 16.75 & 27.91 & 21.79 & 18.28 & 18.28 & 17.18 & 27.89 & 28.48 & 17.20 \\
\hline Palmitic acid (C16:0) & 24.72 & 39.37 & 41.06 & 34.22 & 34.20 & 32.26 & 39.31 & 40.29 & 32.30 \\
\hline Palmitoleic acid (C16:1) & 0.23 & 0.43 & 0.40 & 0.34 & 0.31 & 0.23 & 0.43 & 0.48 & 0.22 \\
\hline Heptadecanoic acid (C17:0) & 4.19 & 7.67 & 5.54 & 4.81 & 4.80 & 4.61 & 7.65 & 7.64 & 4.60 \\
\hline Stearic acid (C18:0) & 0.83 & 1.21 & 1.27 & 1.32 & 1.32 & 1.26 & 1.20 & 1.19 & 1.28 \\
\hline Oleic acid (C18:1) & nd & nd & nd & nd & $\mathrm{Nd}$ & nd & nd & nd & nd \\
\hline Linolenic acid (C18:3) & 0.18 & 0.12 & 0.12 & 0.12 & 0.13 & 0.13 & 0.13 & 0.16 & 0.13 \\
\hline Arachidic acid (C20:0) & 0.23 & 0.19 & 0.31 & 0.33 & 0.33 & 0.30 & 0.19 & 0.22 & 0.31 \\
\hline Arachidonic acid (C20:4) & 0.60 & 0.49 & 0.32 & 0.34 & 0.37 & 0.41 & 0.52 & 0.59 & 0.32 \\
\hline Eicosapentaenoic acid (C20:5) & 0.62 & 0.20 & 0.37 & 0.35 & 0.38 & 0.36 & 0.23 & 0.19 & 0.35 \\
\hline Behenic acid (C22:0) & 0.20 & 0.19 & 0.19 & 0.21 & 0.21 & 0.19 & 0.20 & 0.20 & 0.20 \\
\hline Erucic acid (C22:1) & 0.07 & 0.02 & 0.04 & 0.07 & 0.09 & nd & 0.02 & 0.03 & nd \\
\hline Clupanodonic acid (C22:5) & 8.94 & 2.56 & 4.57 & 4.65 & 5.95 & 6.63 & 2.69 & 2.24 & 5.45 \\
\hline Docosahexaenoic acid (C22:6) & 35.99 & 9.32 & 16.81 & 20.22 & 21.95 & 24.22 & 9.47 & 8.59 & 21.23 \\
\hline Lignoceric acid (C24:0) & 0.37 & 0.20 & 0.30 & 0.43 & 0.43 & 0.51 & 0.21 & 0.23 & 0.57 \\
\hline Others & 3.35 & 4.04 & 2.76 & 6.76 & 3.40 & 3.42 & 5.22 & 3.98 & 8.83 \\
\hline Total (\%) & 100 & 100 & 100 & 100 & 100 & 100 & 100 & 100 & 100 \\
\hline
\end{tabular}

${ }^{\mathrm{a}}$ Data are expressed as mean \pm standard deviation of three replicates. The cells were collected at $96 \mathrm{~h}$ of cultivation. The data represent the percentage of individual fatty acid over the total fatty acids. nd; not detect, N; Paknakhon mangrove forest, P; Pakpanang mangrove forest, and T; Thasala mangrove forest. 
http://wjst.wu.ac.th

The highest squalene production was found in Pakphanang (between 0.1 to $4.78 \mathrm{mg} / \mathrm{g}$ ), and then the Paknakhon strains (between 0.07 to $2.82 \mathrm{mg} / \mathrm{g}$ ), while the lowest was obtained from Thasala (between 0.06 to $0.21 \mathrm{mg} / \mathrm{g}$ ) (Table 3). The squalene content of these isolates also varied significantly. The highest squalene content of $4.78 \mathrm{mg} / \mathrm{g}$ was detected in Aurantiochytrium sp. P5/2, which was higher than those of Thraustochytrium ACEM6063 (0.1 mg/g) [15], Schizochytrium mangrovei FB1 (0.162 mg/g) [14], and Aurantiochytrium BR-MP4-A1 $(0.182 \mathrm{mg} / \mathrm{g})$ [23]. These results lay the basis for the further improvement of squalene production by Aurantiochytrium sp. P5/2 through process optimization at an industrial scale.

\section{Molecular phylogeny of nine Thraustochytrid strains}

Nine Thraustochytrid strains were selected for $18 \mathrm{~S}$ rRNA genetic identification. These nine sequences, together with other Thraustochytrid sequences, were used to construct a phylogenetic tree using PhyML and TreeDyn programs. To group the phylogenetic analysis of the family Thraustochytriaceae, the Prorocentrum genus was used as an outgroup. All nine Thraustochytrid isolates were identified as species of Aurantiochytrium sp. From analyzing the sequence of the 18S rDNA gene, it was found that the nine isolates of Thraustochytrid were closely related to the genus Auratiochytrium, with a relationship similarity of $83-99 \%$. This shows all nine isolates were closely related to Thraustochytrid-producing high DHA and squalene, such as Aurantiochytrium sp. BL10, which can produce high DHA reaching up to $59 \mathrm{~g} / \mathrm{L}$ [24], Aurantiochytrium sp. KRS101, which can produce 50.2 g/L of DHA [25], and Aurantiochytrium BR-MP4-A1 isolate, from a Hong Kong mangrove, which can produce squalene with about $0.18 \mathrm{mg} / \mathrm{g}$ of biomass [23] (Figure 2).

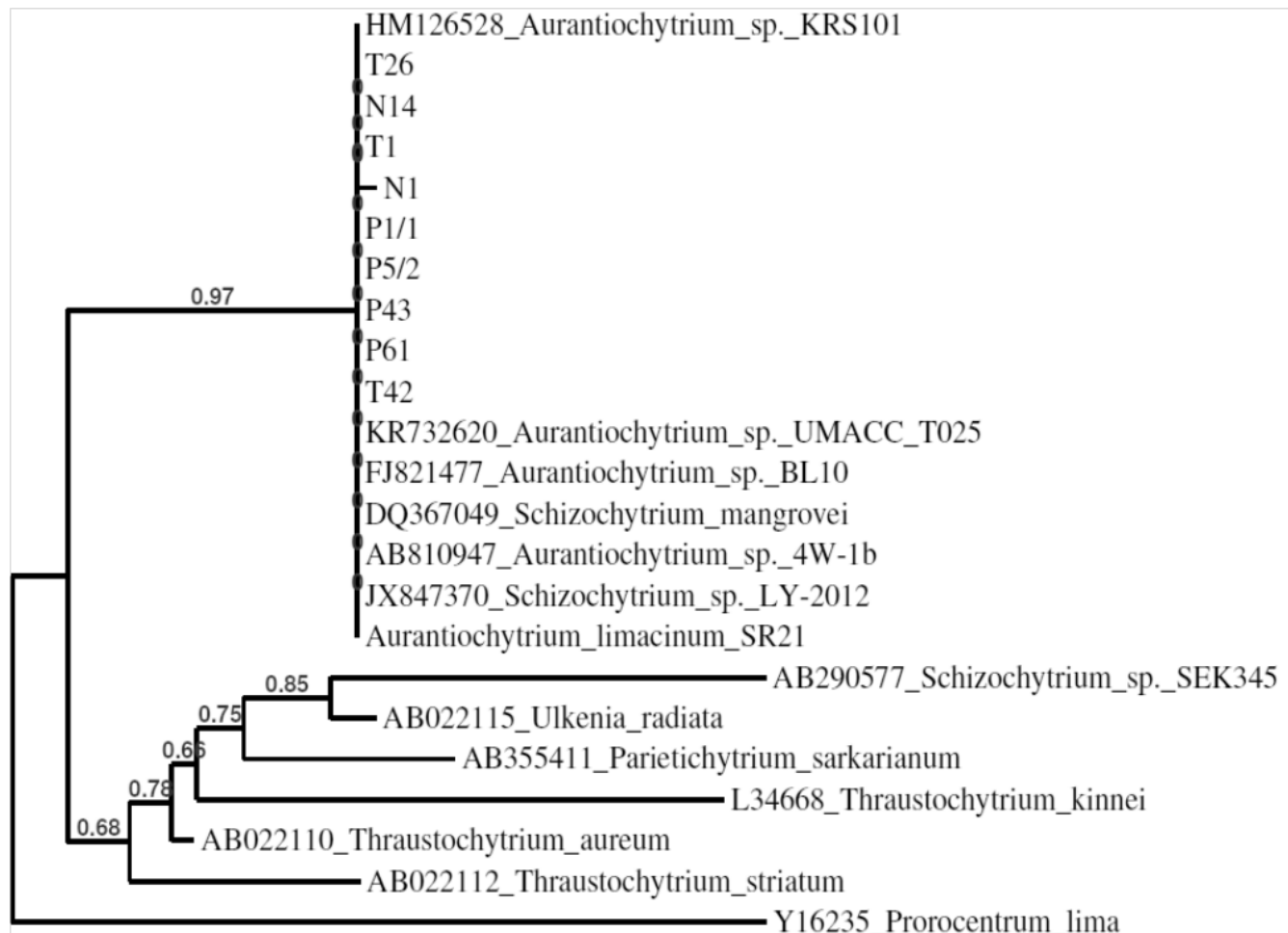

0.1

Figure 2 Molecular analysis based on complete alignment of the 18s rRNA gene. The phylogenetical tree was performed with the genera belonging to the Thraustochytriaceae family and using Prorocentrum lima as an outgroup. 


\section{Conclusions}

In conclusion, nine isolates of heterotrophic thraustochytrid, capable of producing quantities of fatty acid and squalene, were successfully isolated from Nakhon Si Thammarat mangrove habitats. Morphological characterization, along with molecular identification, revealed that these strains showed close similarity to Aurantiochytrium sp. of the family Thraustochytridae. They are able to produce 7.51 to $17.43 \mathrm{mg}$ of dry biomass per gram of culture. The fatty acid profile of isolates comprised mainly saturated fatty acids, dominated particularly by palmitic acid (24.72 - $41.06 \%$ FTA) and, among unsaturated fatty acids, DHA was the highest (8.59-35.99 \% FTA). The squalene contents ranged from 0.06 to $4.78 \mathrm{mg} / \mathrm{g}$. The highest biomass and squalene-accumulation was achieved from strain P5/2, which was identified as Aurantiochytrium sp., with a maximum yield of $4.78 \mathrm{mg} / \mathrm{g}$ at $96 \mathrm{~h}$ of cultivation. These are promising candidates for production organisms for squalene. However, more work is needed on strain selection and studies of the production kinetics; for instance, to which degree the squalene production is growth associated or related to the lipid accumulation seems to vary between strains. The results of this study show that Aurantiochytrium sp. P5/2 is a promising candidate for commercial squalene production and is useful for generating biomass-related products. The results indicate that the growth, lipid profile and fatty-acid profile of Aurantiochytrium sp. P5/2 can be enhanced by adjusting the cultivation conditions and medium composition during fermentation.

\section{Acknowledgements}

This work was supported by Nakhon Si Thammarat Rajabhat University, Thailand.

\section{References}

[1] TF Ko, YM Weng and RYY Chiou. Squalene content and antioxidant activity of Terminalia catappa leaves and seeds. J. Agric. Food Chem. 2002; 50, 5343-8.

[2] TJ Smith. Squalene: Potential chemopreventive agent. Expert Opin. Invest. Drugs. 2000; 9, 1841-8.

[3] A Wei and T Shibamoto. Antioxidant activities of essential oil mixtures toward skin lipid squalene oxidized by UV irradiation. Cutan. Ocul. Toxicol. 2007; 26, 227-33.

[4] ZR Huang, YK Lin and YE Fang. Biological and pharmacological activities of squalene and related compounds: Potential uses in cosmetic dermatology. Molecules 2009; 14, 540-54.

[5] LH Reddy and P Couvreur. Squalene: A natural triterpene for use in disease management and therapy. Adv. Drug Deliv. Rev. 2009; 61, 1412-26.

[6] GS Kelly. Squalene and its potential clinical uses. Altern. Med. Rev. 1999; 4, 29-36.

[7] MJ Bakes and PD Nichols. Lipid, fatty acid and squalene composition of liver oil from six species of deep-sea sharks collected in southern australian waters. Comp. Biochem. Physiol. B: Biochem. Mol. Biol. 1995; 110, 267-75.

[8] HP He, YZ Cai, M Sun and H Corke. Extraction and purification of squalene from Amaranthus grain. J. Agric. Food Chem. 2002 ; 50, 368-72.

[9] JL Guil-Guerrero, F Garcia-Maroto, P Campra-Madrid and F Gomez-Mercado. Occurrence and characterization of oils rich in $\gamma$-linolenic acid. Part II: Fatty acids and squalene from Macaronesian echium leaves. Phytochemistry 2 000; 54, 525-9.

[10] O Popa, NE Babeanu, I Popa, S Nita and CE Dinu-Parvu. Methods for obtaining and determination of squalene from natural sources. Biomed. Res. Int. 2015; 2015, 367202.

[11] MD Salvador, F Aranda, S Gomez-Alonso and G Fregapane. Influence of extraction system, production year and area on Cornicabra virgin olive oil: A study of five crop seasons. Food Chem. 2003; 80, 359-66.

[12] S Raghukumar. Ecology of the marine protist, the Labyrinthulomycetes (Thraustochytrids and Labyrinthulids). Europ. J. Protistol. 2002; 38, 127-45.

[13] P Singh, Y Liu, L Li and G Wang. Ecological dynamics and biotechnological implicationsof Thraustochytrids from marine habitats. Appl. Microbiol. Biotechnol. 2014; 98, 5789-805. 
[14] Y Jiang, KW Fan, RT Wong and F Chen. Fatty acid composition and squalene content of the marine microalga Schizochytrium mangrovei. J. Agric. Food Chem. 2004; 52, 1196-200.

[15] TE Lewis, PD Nichols and TA McMeekin. Sterol and squalene content of a docosahexaenoic-acidproducing Thraustochytrid: Influence of culture age, temperature, and dissolved oxygen. Mar. Biotechnol. 2001; 3, 439-47.

[16] HT Lu, Y Jiang and F Chen. Preparative separation and purification of squalene from the microalga Thraustochytrium ATCC 26185 by high-speed counter-current chromatography. J. Chromatogr. 2003; 994, 37-43.

[17] R Yokoyama and D Honda. Taxonomic rearrangement of the genus Schizochytrium sensu lato based on morphology, chemotaxonomic characteristics, and $18 \mathrm{~S}$ rRNA gene phylogeny (Thraustochytriaceae, Labyrinthulomycetes: Emendation for Schizochytrium and erection of Aurantiochytrium and Oblongichytrium gen. nov. Mycoscience 2007; 48, 199-211.

[18] A Gupta, A Singh, AR Byreddy, T Thyagarajan, SP Sonkar, AS Mahtur, DK Tuti, CJ Barrow and M Puri. Exploring omega-3 fatty acids, enzymes and biodesel producing Thraustochytrids from Australian and indian marine biodiversity. J. Biotechnol. 2016; 11, 345-55.

[19] HT Lu, Y Jiang and F Chen. Determination of squalene using high performance liquid chromatography with diode array detection. Chromatographia 2004; 59, 367-71.

[20] C Mo, J Douekand B Rinkevich. Development of a PCR strategy for Thraustochytrid identification based on 18S rDNA sequence. Mar. Biol. 2002; 140, 883-9.

[21] C Mo and B Rinkevich. A simple, reliable, and fast protocol for Thraustochytrid DNA extraction. Mar. Biotechnol. 2001; 3, 100-2.

[22] EM Leaño, RSJ Gapasin, B Polohan and LLP Vrijmoed. Growth and fatty acid production of Thraustochytrids from Panay mangroves, Philippines. Fungal Divers. 2003; 12, 111-22.

[23] Q Li, GQ Chen, KW Fan, FP Lu, T Aki and YJ Jiang. Screening and characterization of squaleneproducing Thraustochytrids from Hong Kong mangroves. J. Agric. Food Chem. 2009; 57, 4267-72.

[24] HL Yang, CK Lu, SF Chen and YM Chen. Isolation and characterization of Taiwanese heterotrophic microalgae: screening of strains for docosahexaenoic acid (DHA) production. Mar. Biotechnol. 2010; 12,173-85.

[25] WK Hong, D Rairakhwada, PS Seo, SY Park, BK Hur, CH Kim and JW Seo. Production of lipids containing high levels of docosahexaenoic acid by a newly isolated microalga, Aurantiochytrium sp. KRS101. Appl. Microbiol. Biotechnol. 2011; 164, 1468-80. 